\title{
Low estrogen levels and obesity are associated with shorter telomere lengths in pre- and postmenopausal women
}

\author{
Yun-A Shin ${ }^{1,2 * *}$, Kyoung-Young Lee ${ }^{3}$ \\ 'Department of Prescription and Rehabilitation, College of Sports Science, Dankook University, Cheonan, Korea \\ ${ }^{2}$ Department of Kinesiologic Medical Science, Graduate School Dankook University, Cheonan, Korea \\ ${ }^{3}$ Obesity Institute, Benessere Diet Center, Seoul, Korea
}

The aim of this study was to determine whether there is an association between leukocyte telomere length (LTL), and estrogen level, oxidative stress, cardiovascular disease (CVD) risk factors, and cardiorespiratory fitness (CRF) in pre- and postmenopausal obese women. Fifty-four obese women (premenopausal, $n=25$; postmenopausal, $n=29$ ) were selected to participate in this study. The outcome measurements in the pre- and postmenopausal groups were compared using independent t-tests and Pearson correlation analysis. The estrogen level $(P<0.001)$, $\operatorname{LTL}(P<0.05)$, high-density lipoprotein level $(P<0.05)$, and $\operatorname{CRF}(P<0.001)$ were higher in premenopausal women than in postmenopausal women. The body fat percentage $(P<0.05)$ and triglyceride concentration $(P<0.05)$ were lower in premenopausal women than in postmenopausal women. There were no significant associations between LTL, CVD risk, CRF, and oxidative stress and antioxidant enzyme activity in premenopausal women. The body mass index (BMI) and body fat percentage in postmenopausal women were negatively associated with LTL $(P<0.05)$. When all women were considered (i.e., both pre- and postmenopause), the BMI, percentage of fat, and waist circumference had a negative association with $\operatorname{LTL}(P<0.05)$, and estrogen levels were positively associated with $L T L(P<0.05)$. Decreased estrogen levels after menopause, a pivotal factor in the biology of aging, and obesity were more associated with shorter telomere lengths in pre- and postmenopausal women than aerobic capacity and other CVD risk factors.

Keywords: Telomere, Menopause, Obesity, Estrogen, Cardiovascular disease risk factors

\section{INTRODUCTION}

Telomeres are tandem repeats of hexanucleotide sequences (TTAGGG) that are associated with specialized DNA-protein complexes located at both ends of eukaryotic chromosomes (Blackburn, 1991). Telomeres are essential for stabilization and protection of chromosomal ends from recombination, fusion, and degradation, and for the regulation of cell replicative capacity (Hodes, 1999). When cells divide, the telomere is not fully replicated because of limitations in the DNA polymerases in completing the replication of the ends of the linear molecules, leading to a telomere attrition of 50-200 bp in various human cells (Lansdorp, 2005).

The importance of telomeres in vascular pathobiology has previously been identified. Recently, there has been a special emphasis on insights into the mechanisms that alter telomere homeostasis in response to several atherogenic stimuli and conditions, including estrogen levels, oxidative stress, hypertension, and diabetes. A shorter telomere has been associated with increased risks of cardiovascular disease (CVD) (Aviv, 2002; Edo and Andrés, 2005; Fitzpatrick et al., 2007). CVD risk factors such as insulin resistance, hypertension, and obesity, are associated with up-regulated oxidant stress (Maytin et al., 1999) and shortened telomeres (Nakashima et al., 2004).

Although CVD caused by atherosclerosis is rare in premenopausal women, the incidence of CVD increases after menopause

${ }^{\star}$ Corresponding author: Yun-A Shin (D http://orcid.org/0000-0002-8480-3454 Department of Prescription and Rehabilitation, College of Sports Science, 119 Dankook University, Dandae-ro, Dongnam-gu, Cheonan 31116, Korea Tel: +82-41-550-3831, Fax: +82-41-550-3830, E-mail: shinagel@dankook.ac.kr Received: February 15, 2016 / Accepted: May 6, 2016
This is an Open Access article distributed under the terms of the Creative Commons Attribution Non-Commercial License (http://creativecommons.org/licenses/by-nc/4.0/) which permits unrestricted non-commercial use, distribution, and reproduction in any medium, provided the original work is properly cited. 
(Pitha et al., 2013). Menopause and the rapid changes during the menopausal transition could be important in changing CVD risk factors and atherosclerosis development (Woodard et al., 2011; Zaydun et al., 2006). Lejsková et al. (2011) detected a high prevalence of metabolic CVD risk factors in women before and after menopause (aged 45-54 yr). In addition, they found that the menopausal status was a risk factor for the development of hypertension, which is thought to be potentially mediated through an increased body mass index (BMI) (Cifkova et al., 2008). Increase estrogen levels have also been shown to reduce oxidative stress (Song et al., 2009; Wong et al., 2008) and therefore, may indirectly affect telomere maintenance. However, the in vivo relationship between estrogen and telomere length is not well understood. Determining these relationships would be beneficial to understanding the possible mechanisms by which estrogens influence both CVD and oxidative stress.

Regular physical activity has been known to be an important factor in the prevention and treatment of CVD. Furthermore, physically active individuals are known to have reduced morbidity and mortality associated with health and CVD compared to sedentary controls (Kojda and Hambrecht, 2005). According many studies, regular exercise up-regulates the antioxidant system (McArdle and Jackson, 2000) and stimulates the repair system against oxidative damage (Radák et al., 1999; Sato et al., 2003). Moreover, regular aerobic exercise and high aerobic capacity are associated with a better maintenance of cellular functions during aging compared to sedentary lifestyles (LaRocca et al., 2010).

Despite these previous findings, the association between telomere length and physical activity is not unequivocal. Increasing physical activity has been shown to have a positive correlation with telomere length (Cherkas et al., 2008; Zhu et al., 2011), but the linear association has not been confirmed in all studies (Collins et al., 2003; Ludlow et al., 2008). Furthermore, no association between physical activity and telomere length was found in one previous study (Cassidy et al., 2010). Recently, LaRocca et al. (2010) reported that the leukocyte telomere length (LTL) in older endurance-trained adults was approximately 900 bp greater than that in their sedentary peers, and LTL has a significant positive association with $\mathrm{VO}_{2} \mathrm{max}$. However, telomere length was shown to be influenced by sex because vigorous physical activity in adolescents was positively associated with telomere length in only females (Zhu et al., 2011). Longer LTLs were consistently observed in women compared with men (Aviv et al., 2005), which have been ascribed to the ability of estrogen to up-regulate telomerase and concurrently reduce oxidative stress (Calado, 2009; Song et al., 2009).
It is believed that decreased estrogen levels in women is the main cause of an increased CVD risk prevalence along with increased central adiposity (Poehlman et al., 1995; Toth et al., 2000) and an unfavorable lipid profile after menopause (Agrinier et al., 2010; Kuh et al., 2005). Regular exercise helps relieve stress, enhances overall quality of life, and reduces weight gain and muscle loss, which are the most frequent side effects of menopause (Stojanovska et al., 2015). Furthermore, it has been previously shown that moderate to high level of cardiorespiratory fitness (CRF) due to regular exercise decreased the risk of developing CVD in adults (Blair et al., 1996). However, CRF has not yet been fully examined in a well-characterized population of healthy sedentary and obese pre- and postmenopausal women. Information regarding the telomere length and CRF in pre- and postmenopausal women is also limited.

Based on these previous findings, obese menopausal women may induce oxidative stress, which can cause the development of CVD. Furthermore, a higher CRF due to regular exercise can down-regulate the obesity condition, oxidative stress, and CVD risk factors, which might be a unifying mechanism in decreased telomere shortening. Therefore, we examined whether there is an association between LTL and estrogen level, oxidative stress, CVD risk factors, and CRF in pre- and postmenopausal obese women.

\section{MATERIALS AND METHODS}

\section{Subjects and experiment design}

Fifty-four obese Korea middle-aged women participated in this study. Women who were included in the study had the following criteria: not suffering from metabolic disorders, nonsmokers, not taking anti-inflammatory drugs or steroids, not undergoing hormone replacement therapy, had not undergone surgery within the previous 3 months, and a BMI of $\geq 25 \mathrm{~kg} / \mathrm{m}^{2}$. Informed consent was obtained from all subjects prior to their participation in this study. The study subjects completed questionnaires regarding their medical and exercise history, which included questions pertaining to diseases, age at menopause, alcohol consumption, cigarette smoking, use of anti-inflammatory drugs or steroids, surgical history, duration of exercise, type of exercise, and regular exercise participation within the previous 3 months. The present study was approved by the Institutional Ethnics Committee of Physical Education of Dankook University.

\section{Physical examination}

Anthropometric measurements were performed by trained and 
certified observers. The height, body weight, and body fat percentage of the study participants were recorded (INBODY 3.0, Biospace, Seoul, Korea) and BMI was calculated as weight $(\mathrm{kg}) /$ height $\left(\mathrm{m}^{2}\right)$. Obesity was defined as a BMI $\geq 25 \mathrm{~kg} / \mathrm{m}^{2}$ according to the Korea Society for the Study of Obesity (Korean Society for the Study of Obesity, 2013). Waist circumference (WC) was determined at the level of the natural waist, between the ribs and the iliac crest, at the end of a normal expiration. Blood pressure was measured in duplicate (after a 5-min rest interval), on the right arm with the subjects in a sitting position by qualified physicians or nurses using a standard mercury sphygmomanometer. Hypertension was defined as a systolic blood pressure (SBP) of $\geq 140 \mathrm{mmHg}$ and a diastolic blood pressure (DBP) of $\geq 90$ $\mathrm{mmHg}$.

\section{Blood collection and assessment of biomarkers}

Venous blood samples were obtained from the participants after an overnight fast to measure lipid and glucose levels and avoiding the menstrual cycle to measure estrogen. Blood serum aliquots were stored at $-80^{\circ} \mathrm{C}$ until assayed. Triglyceride (TG) and highdensity lipoprotein cholesterol (HDL-C) levels were measured using the enzymatic colorimetric method and analyzed using the COBAS integra 800 (Roche, Basel, Switzerland). Plasma glucose levels were measured with a commercially available glucose hexokinase kit (ADVIA 1650, Bayer, Tokyo, Japan). Dyslipidemia was defined as a TG level $\geq 150 \mathrm{mg} / \mathrm{dL}$ and HDL-C level $<40$ $\mathrm{mg} / \mathrm{dL}$. Estrogen was assayed by electrochemiluminescence immunoassay using Elecasys 2010 (Roche, Indianapolis, IN, USA).

\section{CRF testing}

The $\mathrm{VO}_{2}$ max of each subject was measured to objectively measure CRF. Subjects were familiarized with treadmill running and were informed of their requirements during the experiment. Afterwards, the participants completed a graded treadmill exercise test to determine their individual $\mathrm{VO}_{2}$ max according to the Bruce Protocol. Metabolic data were collected using open circuit spirometry (Vmax29, Sensormedics, Yorba Linda, CA, USA).

\section{Analysis of oxidative stress and antioxidant enzyme activity}

For both experiments, serum aliquots were stored at $-80^{\circ} \mathrm{C}$ until assayed. A total of $10 \mathrm{~mL}$ of blood was obtained from the subjects before and after exercise testing and overnight fasting. A Diode spectrophotometer (HP8452A, SpectraLab Scienctific Inc., Toronto, Canada) was used to assess the malondialdehyde (MDA) levels in the serum, according to the manufacturer's instructions. Butylated hydroxyl toluene and chromogenic reagent were added to samples and warmed to $45^{\circ} \mathrm{C}$ for $60 \mathrm{~min}$. Absorbance values were obtained spectrophotometrically at $586 \mathrm{~nm}$. The MDA levels were reported as $\mu \mathrm{mol}$ serum. The erythrocyte superoxide dismutase (SOD) and glutathione peroxidase (GPX) activities were assessed by the enzyme-linked immunosorbent assay method using commercially available kits (IBL, Hamburg, Germany).

\section{Analysis of mean telomere length in leukocyte}

DNA samples, extracted from leukocyte, were digested with restriction enzymes Hinf and Risa (1 $\mu$ g each; Roche, Mannheim, Germany). Sixteen DNA samples (17 $\mu \mathrm{g}$ each), high and low DNA control $(17 \mu \mathrm{g}$ each), and 2 DNA ladders $(1 \mathrm{~kb})$ were resolved on a $0.8 \%$ agarose gel $(20 \mathrm{~cm} \times 20 \mathrm{~cm})$ at $100 \mathrm{~V}$ in $1 \times$ TAE buffer. After $8 \mathrm{hr}$, the DNA was depurinated for approximately $5-10 \mathrm{~min}$ in $0.25 \mathrm{bM} \mathrm{HCl}$ solution until the bromophenol blue stain changed its color to yellow, denatured for $15 \mathrm{~min}$ $\times 2$ in $0.5-\mathrm{M} \mathrm{NaOH}, 1.5-\mathrm{M} \mathrm{NaCl}$, and neutralized for $15 \mathrm{~min}$ $\times 2$ in $0.5-\mathrm{M}$ Tris, $3-\mathrm{M} \mathrm{NaCl}, \mathrm{pH} 7.5$. The DNA was transferred overnight to a positively charged nylon membrane using $20 \times$ saline-sodium citrate (SSC). After Southern blot transfer, the transferred DNA was fixed on the wet blotting membrane by ultraviolet-crosslinking $(120 \mathrm{~mJ})$ and membranes were baked at $65^{\circ} \mathrm{C}$ for $4 \mathrm{hr}$. The membranes were prehybridized at $42^{\circ} \mathrm{C}$ with prewarmed DIG Easy Hyb for 4 hr (Roche, Mannheim, Germany) and hybridized overnight at $42^{\circ} \mathrm{C}$ with prewarmed DIG Easy Hyb and a $1-\mu \mathrm{L}$ telomere probe (Roche, Mannheim, Germany). The membranes were washed twice with $2 \times$ SSC for $5 \mathrm{~min}$ and twice with $0.2 \times \mathrm{SSC}$ for $20 \mathrm{~min}$ at $50^{\circ} \mathrm{C}$. After the membranes were washed, telomeric DNA was detected by the chemiluminescence detection procedure (Roche, Mannheim, Germany) and exposed on a radiograph.

\section{Statistical analysis}

All data were represented as mean \pm standard deviation. Differences in the physical characteristics, CVD risk, CFR, and oxidative stress and antioxidant enzyme activity between pre- and postmenopausal women were evaluated using independent $t$-test. Associations between LTL, CVD risk, CRF, and oxidative stress and antioxidant enzyme activity were analyzed using Person correlation analysis. All statistical analyses were performed using the SPSS ver. 17.0 (SPSS Inc., Chicago, IL, USA) and $P$-values $<0.05$ were considered statistically significant. 


\section{RESULTS}

\section{Physical characteristics of subjects according to the menopause state}

The physical characteristics of pre- and postmenopausal women are shown in Table 1. Age $(P<0.001)$ was lower in premenopausal women compared to postmenopausal women. Height $(P<0.05)$, estrogen level $(P<0.001)$, and LTL $(P<0.05)$ were higher in premenopausal women compared to postmenopausal women.

\section{CVD risk factors and CRF of subjects according to the menopause state}

The CVD risk and CRF of pre- and postmenopausal women are shown in Table 2. The percentage of body fat $(P<0.05)$ and TG concentration $(P<0.05)$ were lower in premenopause women compared to postmenopausal women. However, HDL-C level $(P<0.05)$ and CRF $(P<0.001)$ were higher in premenopausal women than those who were postmenopausal.

Table 1. The physical characteristics of subjects according to the menopause state

\begin{tabular}{lccc}
\hline Variable & Premenopause $(\mathrm{n}=25)$ & Postmenopause $(\mathrm{n}=29)$ & Sig \\
\hline Age $(\mathrm{yr})$ & $46.08 \pm 5.27$ & $57.22 \pm 2.52$ & $<0.001^{* * *}$ \\
Height $(\mathrm{cm})$ & $157.55 \pm 3.84$ & $154.81 \pm 4.56$ & $0.021^{*}$ \\
Weight $(\mathrm{kg})$ & $64.47 \pm 7.43$ & $64.37 \pm 9.69$ & 0.967 \\
Estrogen $(\mathrm{pg} / \mathrm{mL})$ & $654.61 \pm 263.55$ & $296.53 \pm 187.79$ & $<0.001^{* * *}$ \\
LTL $(\mathrm{kp})$ & $8.29 \pm 1.97$ & $7.13 \pm 1.89$ & $0.031^{*}$ \\
\hline
\end{tabular}

Values are presented as mean \pm standard deviation.

LTL, leukocyte telomere length.

${ }^{*} P<0.05$. ${ }^{* * *} P<0.001$.

Table 2. Cardiovascular risk factors and cardiorespiratory fitness according to the menopause state

\begin{tabular}{lccc}
\hline Variable & $\begin{array}{c}\text { Premenopause } \\
(\mathrm{n}=25)\end{array}$ & $\begin{array}{c}\text { Postmenopause } \\
(\mathrm{n}=29)\end{array}$ & Sig \\
\hline Body mass index $\left(\mathrm{kg} / \mathrm{m}^{2}\right)$ & $25.91 \pm 2.20$ & $26.83 \pm 3.72$ & 0.285 \\
Body fat $(\%)$ & $31.03 \pm 4.47$ & $33.71 \pm 4.20$ & $0.025^{*}$ \\
Waist circumference $(\mathrm{cm})$ & $82.77 \pm 7.60$ & $83.57 \pm 6.91$ & 0.727 \\
SBP $(\mathrm{mmHg})$ & $121.65 \pm 11.16$ & $126.50 \pm 12.05$ & 0.135 \\
DBP $(\mathrm{mmHg})$ & $81.77 \pm 10.75$ & $86.80 \pm 9.89$ & 0.101 \\
FBG $(\mathrm{mg} / \mathrm{dL})$ & $88.56 \pm 7.02$ & $92.28 \pm 9.04$ & 0.095 \\
HDL-C $(\mathrm{mg} / \mathrm{dL})$ & $53.08 \pm 16.96$ & $44.38 \pm 9.66$ & $0.018^{*}$ \\
Triglyceride $(\mathrm{mg} / \mathrm{dL})$ & $113.14 \pm 51.72$ & $177.47 \pm 102.77$ & $0.010^{*}$ \\
V0 $2 \mathrm{max}(\mathrm{mL} / \mathrm{kg} / \mathrm{min})$ & $33.15 \pm 3.66$ & $27.69 \pm 5.29$ & $<0.001^{* * *}$ \\
\hline
\end{tabular}

Values are presented as mean \pm standard deviation.

SBP, systolic blood pressure; DBP, diastolic blood pressure; FBG, fasting blood glucose; HDL-C, high-density lipoprotein cholesterol.

${ }^{*} P<0.05$. ${ }^{* *} P<0.001$.
Oxidative stress and antioxidant enzyme activity of subjects according to the menopause state

The oxidative stress and antioxidant levels of pre- and postmenopausal women are shown in Table 3. There were no significant differences in the MDA, SOD, and GPX levels between the pre- and postmenopausal groups.

\section{Associations between LTL and CVD risk, CRF, and oxidative stress and antioxidant enzyme activity}

In premenopausal women, there were no significant associations among LTL, CVD risk, CRF, and oxidative stress and antioxidant enzyme activity (Table 4). In postmenopausal women, BMI and the body fat percentage were shown to have a negative association with LTL $(P<0.05)$. In total (i.e., both pre- and postmenopausal women), the BMI, body fat percentage, and WC were shown to

Table 3. Oxidative stress and antioxidant levels of subjects according to their state of menopause

\begin{tabular}{lccc}
\hline Variable & Premenopause $(\mathrm{n}=25)$ & Postmenopause $(\mathrm{n}=29)$ & Sig \\
\hline MDA $(\mu \mathrm{mol})$ & $1.39 \pm 0.75$ & $1.69 \pm 0.85$ & 0.203 \\
$\mathrm{SOD}(\mathrm{U} / \mathrm{m})$ & $1.34 \pm 0.71$ & $1.26 \pm 0.59$ & 0.677 \\
$\mathrm{GPx}(\mathrm{nmol} / \mathrm{min} / \mathrm{mL})$ & $152.05 \pm 29.61$ & $152.36 \pm 24.53$ & 0.969 \\
\hline
\end{tabular}

Values are presented as mean \pm standard deviation.

MDA, malondialdehyde; SOD, superoxide dismutase; GPx, glutathione peroxidase.

Table 4. The association between mean leukocyte telomere length and cardiovascular risk factors, cardiorespiratory fitness, and oxidative stress and antioxidant enzyme activities in pre- and postmenopausal women

\begin{tabular}{lccc}
\hline & \multicolumn{3}{c}{ Leukocyte telomere length } \\
\cline { 2 - 4 } Variable & $\begin{array}{c}\text { Premenopause } \\
(\mathrm{n}=25)\end{array}$ & $\begin{array}{c}\text { Postmenopause } \\
(\mathrm{n}=29)\end{array}$ & $\begin{array}{c}\text { Total } \\
(\mathrm{n}=54)\end{array}$ \\
\hline Body mass index $\left(\mathrm{kg} / \mathrm{m}^{2}\right)$ & -0.035 & $-0.391^{*}$ & $-0.293^{*}$ \\
Body fat $(\%)$ & 0.019 & $-0.408^{*}$ & $-0.272^{*}$ \\
Waist circumference $(\mathrm{cm})$ & -0.247 & -0.288 & $-0.310^{*}$ \\
SBP $(\mathrm{mmHg})$ & 0.020 & 0.057 & -0.025 \\
DBP $(\mathrm{mmHg})$ & -0.059 & -0.080 & -0.133 \\
FBG $(\mathrm{mg} / \mathrm{dL})$ & -0.320 & 0.042 & -0.162 \\
HDL-C $(\mathrm{mg} / \mathrm{dL})$ & 0.297 & -0.336 & 0.129 \\
Triglyceride $(\mathrm{mg} / \mathrm{dL})$ & -0.240 & 0.196 & -0.052 \\
VO $2 \mathrm{max}(\mathrm{mL} / \mathrm{kg} / \mathrm{min})$ & -0.087 & -0.210 & 0.031 \\
MDA $(\mu \mathrm{mol})$ & -0.077 & 0.071 & -0.021 \\
SOD $(\mathrm{U} / \mathrm{m})$ & -0.072 & -0.153 & -0.094 \\
GPx $(\mathrm{nmol} / \mathrm{min} / \mathrm{mL})$ & -0.290 & 0.159 & -0.032 \\
Estrogen $(\mathrm{pg} / \mathrm{mL})$ & 0.376 & 0.018 & $0.286^{*}$ \\
\hline SBP & &
\end{tabular}

SBP, systolic blood pressure; DBP, diastolic blood pressure; FBG, fasting blood glucose; HDL-C, high-density lipoprotein cholesterol; TG, triglyceride; MDA, malondialdehyde; SOD, superoxide dismutase; GPx, glutathione peroxidase.

${ }^{*} P<0.05$. 
have a negative association with LTL $(P<0.05)$, but estrogen level was shown to have a positive association with LTL $(P<0.05)$.

\section{DISCUSSION}

The main findings of this study were as follows: (a) LTL was different between pre- and postmenopausal women, (b) estrogen level was associated with telomere attrition, and (c) increased BMI and body fat percentage contributed to accelerated telomere attrition, especially in postmenopausal women. The role of estrogen in modifying vascular disease risk in women is contentious. Menopause is associated with increased risk for ischemic heart disease and cerebrovascular disease, which are the collective main causes of morbidity and mortality in women of developed nations (Lin et al., 2011).

Estrogen level and LTL were significantly different between pre- and postmenopausal women in this study. In previous studies, it has been reported that estrogen increases telomerase activity (Kyo et al., 1999) and higher estrogen levels have antioxidant effects via several mechanisms, such as scavenging free radicals, inhibiting free radical production, and stimulating some enzymes involved in detoxification (Massafra et al., 2000; Römer et al., 1997; Sack et al., 1994). However, we did not find any difference in the oxidative stress and antioxidants levels and estrogen levels in pre- and postmenopausal women. Moreover, estrogen levels were observed to have a positive association with LTL. According to these result, estrogens affect the LTL and may have contributed to the observed difference in LTL between in pre- and postmenopausal women regardless of their oxidative stress and antioxidant enzyme activities.

No significant differences in SBP, DBP, and fasting blood glucose levels were observed between pre- and postmenopausal women in our study, which was similar to the studies conducted by Chang et al. (2000) and He et al. (2012). Furthermore, these risk factors were not shown to be related to LTL. A high prevalence of dyslipidemia and high blood lipid levels were associated with menopause in this study, and these results were consistent with other findings from Western countries and China (Agrinier et al., 2010; Feng et al., 2008; Kuh et al., 2005). Changes in the lipid profile were observed to occur as early as the perimenopause period in several studies (Agrinier et al., 2010; Fukami et al., 1995), which could be related to decreased estrogen levels during menopause (Everson et al., 1991; Walsh et al., 1991).

The telomere length was not correlated with CVD risk in our study despite a higher TG and lower HDL-C levels in women who were postmenopausal compared to those who were premenopausal. It was reported that HDL-C levels were independently and positively associated with LTL during childhood and adulthood in a previous study (Chen et al., 2009) and in cross-sectional study conducted in high-risk populations (Adaikalakoteswari et al., 2007). A putative explanation for this association is that HDL-C has antioxidant and anti-inflammatory properties, and LTL ostensibly reflects the cumulative burden of inflammation and oxidative stress (Nofer et al., 2005). Low HDL-C level phenotypes have been shown to display elevated oxidative stress and accelerated senescence, which suggests that a reduced LTL could be a biomarker of increased oxidative stress and inflammation (Kontush et al., 2005). We were unable to determine whether inflammation, oxidative stress, CVD risk, or their combination contributes to accelerated telomere attrition that accompanies menopause in this study. However, the MDA level of the subjects was approximately $0.45-3.92 \mu \mathrm{mol}$, which is not a high stress condition. Epel et al. (2004) reported that a person with low oxidative stress has a longer telomere length compared to a person in a high oxidative stress condition. The telomere length did not correlate with CVD risk in this study because the participants were not severely obese.

Regular physical activity reduces the risk for obesity, type 2 diabetes, hypertension, and cancer in adults. Furthermore, physical activity is positively associated with LTL in adults, which suggests an antiaging property (Cherkas et al., 2008; LaRocca et al., 2010; Ludlow et al., 2008; Ponsot et al., 2008). Physical activity during leisure time was correlated with a longer telomere length in the United Kingdom Adult Twin Registry (Ludlow et al., 2008). Puterman et al. (2010) found that the relationship between stress and short telomeres was attenuated in women who exercised the amount recommended by the Center for Disease Control and Prevention (an average of 75 min of vigorous activity/week). However, Savela et al. (2013) reported that long-term moderate physical activity levels during leisure time were associated with longer mean LTLs compared to both low and high physical activity levels. In a study of 69 volunteers aged 50-70 yr, Ludlow et al. (2008) also reported that moderate physical activity levels were associated with longer LTLs compared to both the lowest and the highest quartiles of physical activity. Furthermore, Collins et al. (2003) supported these findings of endurance athletes by indicating that participants with fatigued athlete myopathic syndrome had a severe reduction in skeletal muscle DNA telomere length compared to 13 healthy athletes.

CRF, estrogen levels, and LTL were shown to be significantly 
different between pre- and postmenopausal women in this study; however, CRF was not associated with LTL. The various mechanisms by which exercise may affect aging at the cellular level are currently not fully understood; however, lower basal levels of reactive oxygen species in mitochondria, increased activity of antioxidants and damage repair enzymes (Baar, 2004; Radak et al., 2008), and up-regulation of neurotropic factors (Dishman et al., 2006) have been proposed to be involved. Telomere length has been considered a possible link between physical activity and health (Ludlow and Roth, 2011). However, LaRocca et al. (2010) reported that LTL is not influenced by aerobic exercise among young subjects (18-32 yr); however, LTL was related to regular vigorous aerobic exercise and maximal aerobic exercise capacity in aged healthy humans. These results were due to modulations of $\mathrm{VO}_{2}$ max by habitual aerobic exercise; however, up to $~ 50 \%$ of $\mathrm{VO}_{2} \max$ is determined primarily by genetic factors (Bouchard et al., 1998). The subjects of this study were obese women, which may have affected the telomere length more than $\mathrm{VO}_{2}$ max regardless of their menopause state.

Menopause leads to changes in metabolic functions in women, which may act as risk factors for CVD. Therefore, the menopause state has been considered as another, but unique, CVD risk factor for women in addition to aging. In Rosamond et al. (2007), CVD risk increased rapidly and to a greater degree in menopausal women than men. Gordon et al. (1978) noted an increase in the incidence of coronary heart disease after menopause in a cohort of Framingham women. Furthermore, in a population study in the Netherlands, Witteman et al. (1989) observed that women having natural menopause had a 3 times greater risk of atherosclerosis than premenopausal women.

According to the results of this study, body compositions were not significantly different between the pre- and postmenopausal groups, except for body fat percentage because all subjects were in an obese condition. However, LTL was negatively associated with BMI, WC, and body fat percentage in the total study population (i.e., both pre- and postmenopausal women). Recently, Lee et al. (2011) reported that BMI, WC, hip circumference, total body fat, and visceral adipose tissue volume were all inversely associated with telomere length. Telomere lengths measured from subcutaneous adipocytes of obese patients were significantly lower than patients who were never obese (Moreno-Navarrete et al., 2010). Obesity is associated with increased inflammation because fat tissues are a major source of inflammatory cytokines (Keaney et al., 2003). Inflammation is a source of oxidative stress (Festa et al., 2001), which plays a critical role in the pathogenesis of various diseases (Brownlee, 2001). Inflammation also promotes increased leukocyte turnover, which would enhance telomere attrition (Gardner et al., 2007). In addition, increased adiposity is accompanied by angiogenesis to accommodate the growing metabolic needs of the expanding fat mass (Rupnick et al., 2002), which explains the increased central and total blood volume of obese subjects (Oren et al., 1996). Therefore, obese individuals may need to increase the total number of circulating leukocytes to maintain the peripheral leukocyte pool. Although the body fat percentage was different between the pre- and postmenopause groups, the subjects included in this study were all obese. BMI and body fat percentage were negatively associated with LTL in postmenopause women. Therefore, the obese condition contributed to accelerated telomere attrition, which accompanies body fat gain especially in postmenopause conditions.

In conclusion, a decreased estrogen level after menopause is related to dyslipidemia (i.e., higher TG and lower HDL-C levels) and a shorter telomere length compared to premenopause. $\mathrm{VO}_{2} \mathrm{~m}$ ax did not affect the LTL; however, we observed that obesity conditions (i.e., BMI, body fat, WC, and estrogen levels) were associated with LTL in the total study population. BMI and body fat percent were especially related to LTL in postmenopausal women. Decreased estrogen levels after menopause is considered a pivotal factor in aging, and both low estrogen levels and obesity conditions were more associated with shorter telomere lengths in preand postmenopause women than aerobic capacity and other CVD risk factors. Therefore, obesity should be treated with an emphasis on LTL especially in postmenopausal women because of their aging process.

\section{CONFLICT OF INTEREST}

No potential conflict of interest relevant to this article was reported.

\section{REFERENCES}

Adaikalakoteswari A, Balasubramanyam M, Ravikumar R, Deepa R, Mohan V. Association of telomere shortening with impaired glucose tolerance and diabetic macroangiopathy. Atherosclerosis 2007;195:83-89.

Agrinier N, Cournot M, Dallongeville J, Arveiler D, Ducimetière P, Ruidavets JB, Ferrières J. Menopause and modifiable coronary heart disease risk factors: a population based study. Maturitas 2010;65:237-243. Aviv A. Telomeres, sex, reactive oxygen species, and human cardiovascular aging. J Mol Med (Berl) 2002;80:689-695. 
Aviv A, Shay J, Christensen K, Wright W. The longevity gender gap: are telomeres the explanation? Sci Aging Knowledge Environ 2005; 2005:pe16.

Baar K. Involvement of PPAR gamma co-activator-1, nuclear respiratory factors 1 and 2, and PPAR alpha in the adaptive response to endurance exercise. Proc Nutr Soc 2004;63:269-273.

Blackburn EH. Structure and function of telomeres. Nature 1991;350:569573.

Blair SN, Kampert JB, Kohl HW 3rd, Barlow CE, Macera CA, Paffenbarger RS Jr, Gibbons LW. Influences of cardiorespiratory fitness and other precursors on cardiovascular disease and all-cause mortality in men and women. JAMA 1996;276:205-210.

Bouchard C, Daw EW, Rice T, Pérusse L, Gagnon J, Province MA, Leon AS, Rao DC, Skinner JS, Wilmore JH. Familial resemblance for $\mathrm{VO}_{2}$ max in the sedentary state: the HERITAGE family study. Med Sci Sports Exerc 1998;30:252-258.

Brownlee M. Biochemistry and molecular cell biology of diabetic complications. Nature 2001;414:813-820.

Calado RT. Telomeres and marrow failure. Hematology Am Soc Hematol Educ Program. 2009:338-343.

Cassidy A, De Vivo I, Liu Y, Han J, Prescott J, Hunter DJ, Rimm EB. Associations between diet, lifestyle factors, and telomere length in women. Am J Clin Nutr 2010;91:1273-1280.

Chang CJ, Wu CH, Yao WJ, Yang YC, Wu JS, Lu FH. Relationships of age, menopause and central obesity on cardiovascular disease risk factors in Chinese women. Int J Obes Relat Metab Disord 2000;24:1699-1704.

Chen W, Gardner JP, Kimura M, Brimacombe M, Cao X, Srinivasan SR, Berenson GS, Aviv A. Leukocyte telomere length is associated with HDL cholesterol levels: the Bogalusa heart study. Atherosclerosis 2009;205:620-625.

Cherkas LF, Hunkin JL, Kato BS, Richards JB, Gardner JP, Surdulescu GL, Kimura M, Lu X, Spector TD, Aviv A. The association between physical activity in leisure time and leukocyte telomere length. Arch Intern Med 2008;168:154-158.

Cifkova R, Pitha J, Lejskova M, Lanska V, Zecova S. Blood pressure around the menopause: a population study. J Hypertens 2008;26:19761982.

Collins M, Renault V, Grobler LA, St Clair Gibson A, Lambert MI, Wayne Derman E, Butler-Browne GS, Noakes TD, Mouly V. Athletes with exercise-associated fatigue have abnormally short muscle DNA telomeres. Med Sci Sports Exerc 2003;35:1524-1528.

Dishman RK, Berthoud HR, Booth FW, Cotman CW, Edgerton VR, Fleshner MR, Gandevia SC, Gomez-Pinilla F, Greenwood BN, Hillman CH, Kramer AF, Levin BE, Moran TH, Russo-Neustadt AA, Salamone JD, Van Hoomissen JD, Wade CE, York DA, Zigmond MJ. Neurobiology of exercise. Obesity (Silver Spring) 2006;14:345-356.

Edo MD, Andrés V. Aging, telomeres, and atherosclerosis. Cardiovasc Res 2005;66:213-221.

Epel ES, Blackburn EH, Lin J, Dhabhar FS, Adler NE, Morrow JD, Cawthon RM. Accelerated telomere shortening in response to life stress. Proc Natl Acad Sci U S A 2004;101:17312-17315.

Everson GT, McKinley C, Kern F Jr. Mechanisms of gallstone formation in women. Effects of exogenous estrogen (Premarin) and dietary cholesterol on hepatic lipid metabolism. J Clin Invest 1991;87:237-246.

Feng Y, Hong X, Wilker E, Li Z, Zhang W, Jin D, Liu X, Zang T, Xu X, Xu $X$. Effects of age at menarche, reproductive years, and menopause on metabolic risk factors for cardiovascular diseases. Atherosclerosis 2008;196:590-597.

Festa A, D'Agostino R Jr, Williams K, Karter AJ, Mayer-Davis EJ, Tracy $\mathrm{RP}$, Haffner SM. The relation of body fat mass and distribution to markers of chronic inflammation. Int J Obes Relat Metab Disord 2001;25:1407-1415.

Fitzpatrick AL, Kronmal RA, Gardner JP, Psaty BM, Jenny NS, Tracy RP, Walston J, Kimura M, Aviv A. Leukocyte telomere length and cardiovascular disease in the cardiovascular health study. Am J Epidemiol 2007;165:14-21.

Fukami K, Koike K, Hirota K, Yoshikawa H, Miyake A. Perimenopausal changes in serum lipids and lipoproteins: a 7-year longitudinal study. Maturitas 1995;22:193-197.

Gardner JP, Kimura M, Chai W, Durrani JF, Tchakmakjian L, Cao X, Lu X, Li G, Peppas AP, Skurnick J, Wright WE, Shay JW, Aviv A. Telomere dynamics in macaques and humans. J Gerontol A Biol Sci Med Sci 2007;62:367-374.

Gordon T, Kannel WB, Hjortland MC, McNamara PM. Menopause and coronary heart disease. The Framingham Study. Ann Intern Med 1978;89:157-161.

He L, Tang X, Li N, Wu YQ, Wang JW, Li JR, Zhang ZX, Dou HD, Liu JJ, Yu LP, Xu HT, Zhang JG, Hu YH. Menopause with cardiovascular disease and its risk factors among rural Chinese women in Beijing: a population-based study. Maturitas 2012;72:132-138.

Hodes RJ. Telomere length, aging, and somatic cell turnover. J Exp Med 1999;190:153-156.

Keaney JF Jr, Larson MG, Vasan RS, Wilson PW, Lipinska I, Corey D, Massaro JM, Sutherland P, Vita JA, Benjamin EJ; Framingham Study. Obesity and systemic oxidative stress: clinical correlates of oxidative stress in the Framingham Study. Arterioscler Thromb Vasc Biol 2003; 23:434-439.

Kojda G, Hambrecht R. Molecular mechanisms of vascular adaptations to exercise. Physical activity as an effective antioxidant therapy? Cardiovasc Res 2005;67:187-197. 
Kontush A, de Faria EC, Chantepie S, Chapman MJ. A normotriglyceridemic, low HDL-cholesterol phenotype is characterised by elevated oxidative stress and HDL particles with attenuated antioxidative activity. Atherosclerosis 2005;182:277-285.

Korean Society for the Study of Obesity. Guidelines of obesity. Seoul: Korean Medicine Press; 2013

Kuh D, Langenberg C, Hardy R, Kok H, Cooper R, Butterworth S, Wadsworth ME. Cardiovascular risk at age 53 years in relation to the menopause transition and use of hormone replacement therapy: a prospective British birth cohort study. BJOG 2005;112:476-485.

Kyo S, Takakura M, Kanaya T, Zhuo W, Fujimoto K, Nishio Y, Orimo A, Inoue M. Estrogen activates telomerase. Cancer Res 1999;59:5917-5921.

Lansdorp PM. Major cutbacks at chromosome ends. Trends Biochem Sci 2005;30:388-395.

LaRocca TJ, Seals DR, Pierce GL. Leukocyte telomere length is preserved with aging in endurance exercise-trained adults and related to maximal aerobic capacity. Mech Ageing Dev 2010;131:165-167.

Lee M, Martin H, Firpo MA, Demerath EW. Inverse association between adiposity and telomere length: The Fels Longitudinal Study. Am J Hum Biol 2011;23:100-106.

Lejsková M, Alušík S, Suchánek M, Zecová S, Pitha J. Menopause: clustering of metabolic syndrome components and population changes in insulin resistance. Climacteric 2011;14:83-91.

Lin KH, Liou TL, Hsiao LC, Hwu CM. Clinical and biochemical indicators of homeostasis model assessment-estimated insulin resistance in postmenopausal women. J Chin Med Assoc 2011;74:442-447.

Ludlow AT, Roth SM. Physical activity and telomere biology: exploring the link with aging-related disease prevention. J Aging Res 2011; 2011:790378.

Ludlow AT, Zimmerman JB, Witkowski S, Hearn JW, Hatfield BD, Roth $\mathrm{SM}$. Relationship between physical activity level, telomere length, and telomerase activity. Med Sci Sports Exerc 2008;40:1764-1771.

Massafra C, Gioia D, De Felice C, Picciolini E, De Leo V, Bonifazi M, Bernabei A. Effects of estrogens and androgens on erythrocyte antioxidant superoxide dismutase, catalase and glutathione peroxidase activities during the menstrual cycle. J Endocrinol 2000;167:447-452.

Maytin M, Leopold J, Loscalzo J. Oxidant stress in the vasculature. Curr Atheroscler Rep 1999;1:156-164.

McArdle A, Jackson MJ. Exercise, oxidative stress and ageing. J Anat 2000;197 Pt 4:539-541.

Moreno-Navarrete JM, Ortega F, Sabater M, Ricart W, Fernández-Real $\mathrm{JM}$. Telomere length of subcutaneous adipose tissue cells is shorter in obese and formerly obese subjects. Int J Obes (Lond) 2010;34:13451348.

Nakashima H, Ozono R, Suyama C, Sueda T, Kambe M, Oshima T. Telo- mere attrition in white blood cell correlating with cardiovascular damage. Hypertens Res 2004;27:319-325.

Nofer JR, Walter M, Assmann G. Current understanding of the role of high-density lipoproteins in atherosclerosis and senescence. Expert Rev Cardiovasc Ther 2005;3:1071-1086.

Oren S, Grossman E, Frohlich ED. Arterial and venous compliance in obese and nonobese subjects. Am J Cardiol 1996;77:665-667.

Pitha J, Lesná K, Sekerkova A, Poledne R, Kovář J, Lejsková M, Dvořáková $\mathrm{H}$, Adámková S, Lánská V, Bobak M. Menopausal transition enhances the atherogenic risk of smoking in middle aged women. Int J Cardiol 2013;168:190-196.

Poehlman ET, Toth MJ, Bunyard LB, Gardner AW, Donaldson KE, Colman E, Fonong T, Ades PA. Physiological predictors of increasing total and central adiposity in aging men and women. Arch Intern Med 1995;155:2443-2448.

Ponsot E, Lexell J, Kadi F. Skeletal muscle telomere length is not impaired in healthy physically active old women and men. Muscle Nerve 2008;37:467-472.

Puterman E, Lin J, Blackburn E, O'Donovan A, Adler N, Epel E. The power of exercise: buffering the effect of chronic stress on telomere length. PLoS One 2010;5:e10837.

Radak Z, Chung HY, Koltai E, Taylor AW, Goto S. Exercise, oxidative stress and hormesis. Ageing Res Rev 2008;7:34-42.

Radák Z, Kaneko T, Tahara S, Nakamoto H, Ohno H, Sasvári M, Nyakas C, Goto S. The effect of exercise training on oxidative damage of lipids, proteins, and DNA in rat skeletal muscle: evidence for beneficial outcomes. Free Radic Biol Med 1999;27:69-74.

Römer W, Oettel M, Menzenbach B, Droescher P, Schwarz S. Novel estrogens and their radical scavenging effects, iron-chelating, and total antioxidative activities: 17 alpha-substituted analogs of delta 9(11)-dehydro-17 beta-estradiol. Steroids 1997;62:688-694.

Rosamond W, Flegal K, Friday G, Furie K, Go A, Greenlund K, Haase N, Ho M, Howard V, Kissela B, Kittner S, Lloyd-Jones D, McDermott M, Meigs J, Moy C, Nichol G, O’Donnell CJ, Roger V, Rumsfeld J, Sorlie P, Steinberger J, Thom T, Wasserthiel-Smoller S, Hong Y; American Heart Association Statistics Committee and Stroke Statistics Subcommittee. Heart disease and stroke statistics--2007 update: a report from the American Heart Association Statistics Committee and Stroke Statistics Subcommittee. Circulation 2007;115:e69-171.

Rupnick MA, Panigrahy D, Zhang CY, Dallabrida SM, Lowell BB, Langer $\mathrm{R}$, Folkman MJ. Adipose tissue mass can be regulated through the vasculature. Proc Natl Acad Sci U S A 2002;99:10730-10735.

Sack MN, Rader DJ, Cannon RO 3rd. Oestrogen and inhibition of oxidation of low-density lipoproteins in postmenopausal women. Lancet 1994;343:269-270. 
Sato Y, Nanri H, Ohta M, Kasai H, Ikeda M. Increase of human MTH1 and decrease of 8-hydroxydeoxyguanosine in leukocyte DNA by acute and chronic exercise in healthy male subjects. Biochem Biophys Res Commun 2003;305:333-338.

Savela S, Saijonmaa O, Strandberg TE, Koistinen P, Strandberg AY, Tilvis RS, Pitkälä KH, Miettinen TA, Fyhrquist F. Physical activity in midlife and telomere length measured in old age. Exp Gerontol 2013;48:81-84.

Song JY, Kim MJ, Jo HH, Hwang SJ, Chae B, Chung JE, Kwon DJ, Lew YO, Lim YT, Kim JH, Kim JH, Kim MR. Antioxidant effect of estrogen on bovine aortic endothelial cells. J Steroid Biochem Mol Biol 2009;117: 74-80.

Stojanovska L, Law C, Lai B, Chung T, Nelson K, Day S, Apostolopoulos $\mathrm{V}$, Haines C. Maca reduces blood pressure and depression, in a pilot study in postmenopausal women. Climacteric 2015;18:69-78.

Toth MJ, Tchernof A, Sites CK, Poehlman ET. Effect of menopausal status on body composition and abdominal fat distribution. Int J Obes Relat Metab Disord 2000;24:226-231.

Walsh BW, Schiff I, Rosner B, Greenberg L, Ravnikar V, Sacks FM. Effects of postmenopausal estrogen replacement on the concentrations and metabolism of plasma lipoproteins. N Engl J Med 1991;325:1196-1204.
Witteman JC, Grobbee DE, Kok FJ, Hofman A, Valkenburg HA. Increased risk of atherosclerosis in women after the menopause. BMJ 1989; 298:642-644.

Wong E, Freiberg M, Tracy R, Kuller L. Epidemiology of cytokines: the Women On the Move through Activity and Nutrition (WOMAN) Study. Am J Epidemiol 2008;168:443-453.

Woodard GA, Brooks MM, Barinas-Mitchell E, Mackey RH, Matthews KA, Sutton-Tyrrell K. Lipids, menopause, and early atherosclerosis in Study of Women's Health Across the Nation Heart women. Menopause 2011;18:376-384.

Zaydun G, Tomiyama H, Hashimoto H, Arai T, Koji Y, Yambe M, Motobe $\mathrm{K}$, Hori S, Yamashina A. Menopause is an independent factor augmenting the age-related increase in arterial stiffness in the early postmenopausal phase. Atherosclerosis 2006;184:137-142.

Zhu H, Wang X, Gutin B, Davis CL, Keeton D, Thomas J, Stallmann-Jorgensen I, Mooken G, Bundy V, Snieder H, van der Harst P, Dong Y. Leukocyte telomere length in healthy Caucasian and African-American adolescents: relationships with race, sex, adiposity, adipokines, and physical activity. J Pediatr 2011;158:215-220. 